\title{
EFFECTS OF DOUBLE-STRANDED RNA VIRUSES ON THE REPRODUCTION OF PHAFFIA RHODOZYMA*
}

\author{
Ilona Pfeiffer, ${ }^{1 * *}$ Judit Litter, ${ }^{1}$ Zs. PÉnZes ${ }^{1}$ and Judit Kucsera ${ }^{1}$ \\ ${ }^{1}$ Department of Microbiology, Faculty of Sciences, University of Szeged, Szeged, Hungary \\ ${ }^{2}$ Department of Ecology, Faculty of Sciences, University of Szeged, Szeged, Hungary
}

(Received: August 31, 2000; accepted: October 5, 2000)

\begin{abstract}
DsRNA viruses were transferred from a virus-containing strain to a virus-free strain of Phaffia rhodozy$m a$ by protoplast fusion. The resulting new strain carried all three types of dsRNA of the virus-containing strain and had the electrophoretic karyotype of the virus-free strain. The effects of the dsRNA viruses on the host fitness were checked by following the asexual and the sexual reproductivity. The results demonstrated that viruses have no effect on the growth rate during the lag and log phases of the vegetative reproduction, but the maximum cell numbers in the stationary phase differ significantly. Inconclusive results were obtained as concerns the effects of viruses on the sexual reproduction.
\end{abstract}

Keywords: Phaffia rhodozyma - dsRNA viruses - sexual reproduction - asexual reproduction - fitness

\section{INTRODUCTION}

Cytoplasmic virus-like particles (VLPs) with double-stranded RNA (dsRNA) genomes are very common among fungi, but have been isolated from only some yeast species [1]. They replicate inside the fungal cells and to date there is no evidence of the existence of their extracellular phase. Consequently, their transmission is presumed to occur solely via cytoplasmic contact [11]. The horizontal transmission (virus transmission between members of the same generation) occurs via direct cytoplasmic contact (anastomosis, conjugation and cytoduction) of an infected and an uninfected strain. The transmission between generations from parents to progenies is called vertical transmission [14]. There is evidence indicating that mycoviruses can be transmitted very efficiently vertically via different kinds of spores [4].

VLPs of yeasts are usually cryptic, i.e. their presence does not cause any phenotypic effect. The killer character of the host cell in Saccharomyces cerevisiae [18] and in Ustilago maydis [8] is the only phenotype so far identified that can be ascribed unequivocally to them.

The astaxanthin-producing yeast species Phaffia rhodozyma grows vegetatively by budding $[9,13]$ and reproduces sexually by basidiospores under special cultiva-

\footnotetext{
*Dedicated to Professor Lajos Ferenczy on the occasion of his 70th birthday.

**Corresponding author; e-mail: pfeiffer@bio.u-szeged.hu
} 
tion conditions $[7,10]$. A recent survey demonstrated that both virus-containing and virus-free strains occur among its natural isolates [16]. The purpose of the present study was to transfer dsRNA viruses from a virus-containing strain to a virus-free strain and to determine whether the presence of the viruses has any effect on the efficiency of the reproduction of $P$. rhodozyma.

\section{MATERIAL AND METHODS}

\section{Strains}

Phaffia rhodozyma CBS 6938 leu, vir (virus-free); P. rhodozyma CBS 6938 leu, vir $^{+}$ (this study), P. rhodozyma ATCC 24203 lys, vir ${ }^{+}$(virus-containing), yellow, and $P$. rhodozyma CBS 6938 ile, vir, pink.

\section{Culture conditions}

Strains were grown in $2 \times$ YPD medium ( $1 \%$ yeast extract, $2 \%$ glucose, $2 \%$ peptone) at $20{ }^{\circ} \mathrm{C}$, with shaking at $200 \mathrm{rpm}$. Sporulation was induced on ribitol medium (DWR agar) which contained $0.5 \%$ ribitol and $2.5 \%$ agar.

\section{Protoplast formation and fusion}

Cells of the fusion partners were cultivated in yeast extract-peptone-glucose (2xYPD) liquid medium for 20 hours, collected by centrifugation and pretreated in $1 \%$ 2-mercaptoethanol. The cell wall was digested with $1.5 \%$ snail enzyme $+0.25 \%$ NovoZym 234 (NovoBioLabs, Denmark) in $1 \mathrm{M}$ mannitol. The resulting protoplasts were washed by repeated centrifugation in osmotic stabilizer. For fusion, $5 \times 10^{8}$ protoplasts from each partner were mixed and treated with $20 \%$ polyethylene glycol (PEG, MW 6000) and $100 \mathrm{mM} \mathrm{CaCl}{ }_{2}$ for 20 min [12]. After removal of the PEG solution, the protoplasts were diluted in $0.3 \mathrm{M} \mathrm{CaCl}_{2}$ and embedded into $2 \%$ agar containing $1 \mathrm{M}$ mannitol at $40{ }^{\circ} \mathrm{C}$. The mixture was overlayered onto presolidified selective minimal (MM) medium.

\section{Analysis of fusion hybrids}

Five hybrid colonies were selected at random from the fusion experiment, subcultured in minimal liquid medium and plated onto complete medium (2xYPD $+2 \%$ agar) containing $0.5 \mu \mathrm{g} / \mathrm{ml}$ benomyl as haploidizing agent. In order to check the segregation of the nuclear genetic markers, several individual haploid colonies were isolated and then plated to complete medium. They were replica plated to differently supplemented minimal media, and leu segregants were selected and analysed further. 


\section{Purification of dsRNAs}

The mini-lysate method for fast screening for the presence of dsRNAs was carried out according to a previously published method [16].

\section{Separation of chromosomal DNA by OFAGE}

The method of sample preparation and the electrophoresis conditions were described by Nagy et al. [15].

\section{Effects of viruses on vegetative reproduction}

P. rhodozyma CBS 6938 leu virus-free and virus-containing strains were cultivated in $2 x Y P D$ medium at $20^{\circ} \mathrm{C}$ with shaking at $200 \mathrm{rpm}$. The cell numbers of the strains were monitored by Burker counting every hour.

Statistical analysis. The growth rates of the strains were compared in the lag and logarithmic phases by exponential or linear regression. All data were square root transformed. Cell numbers were means of counts for every measured time point. The slopes of the curves were compared by $t$-tests in pairs (vir ${ }^{+}$and vir $)$for each experiment.

The cell number in the stationary phase was analysed by two-way ANOVA (with factors of time and infection). All counts were entered individually after square root transformation.

\section{Effects of viruses on sexual reproduction of $\mathrm{P}$. rhodozyma}

The vir' ${ }^{+}$and vir $-l e u$ strains were grown in 2 XYPD medium for 16 hours. The culture was spun and washed twice with distilled water and, after centrifugation, $20 \mu 1$ amounts of sediment were placed on a Petri dish with DWR medium to promote zygote formation and sporulation [10]. Sporulating zygotes were obtained after incubation for 5 to 10 days at $18{ }^{\circ} \mathrm{C}$. The numbers of vegetative cells versus conjugating cells were counted. For measurement of the recombination frequency, the $\operatorname{vir}^{+}$and vir leu strains were crossed with the $i$-leu strain (originating from the same wild-type strain); they were subjected to sporulation, and the ratio of the resulting prototrophic versus auxotrophic colonies was determined.

Statistical analysis. Data were compared for independence of conjugation and infection by the $\chi^{2}$ test (heterogeneity $\chi^{2}=38.51, \mathrm{n}=193748,0.01>\mathrm{p}>0.001$ ). All 19 experiments were evaluated independently because of the lack of homogeneity. 


\section{RESULTS}

\section{Creating a new virus-containing strain}

The leu auxotrophic strain (vir-) was complemented by a lys auxotrophic strain $\left(\mathrm{vir}^{+}\right)$ via protoplast fusion and their prototrophic hybrids were isolated. The dsRNA contents of 5 isolates were checked by agarose gel electrophoresis. All of them contained the 3 dsRNA bands $(4.3 \mathrm{~kb}, 3.7 \mathrm{~kb}$ and $0.97 \mathrm{~kb})$ characteristic of the lys vir' strain (Fig. 1). To obtain haploid progenies, the hybrids were treated with the haploidizing agent benomyl. Several isolates having a leu marker were isolated and their chromosomal constitutions were determined by pulse field gel electrophoresis (OFAGE). From these experiments we obtained one strain $\left(l e u \mathrm{vir}^{+}\right)$which contained the dsRNA pattern of the donor; its chromosomal DNA pattern was the same as that of the recipient (Fig. 2).

\section{Effect of infection on reproductivity}

The vegetative reproduction of the strains CBS 6938 leu, vir and CBS 6938 leu, vir ${ }^{+}$ was monitored by counting the cell number every hour in a Burker chamber. From these data, the growth curves of the strains were constructed (Fig. 3). Statistical

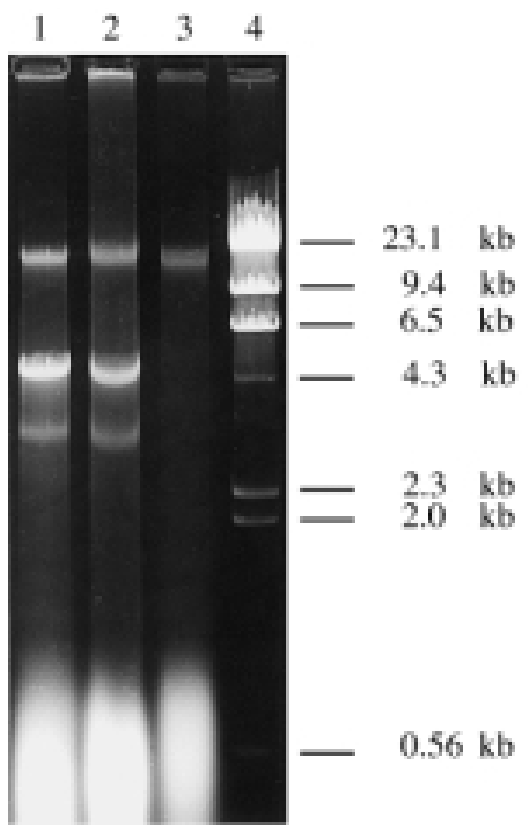

Fig. 1. dsRNA pattern of P. rhodozyma strains. Lane 1. ATCC 24203 lys, vir ${ }^{+}$; lane 2. CBS 6938 leu, vir'; lane 3. CBS 6938 leu, vir; lane 4. HindIII-digested $\gamma$ DNA

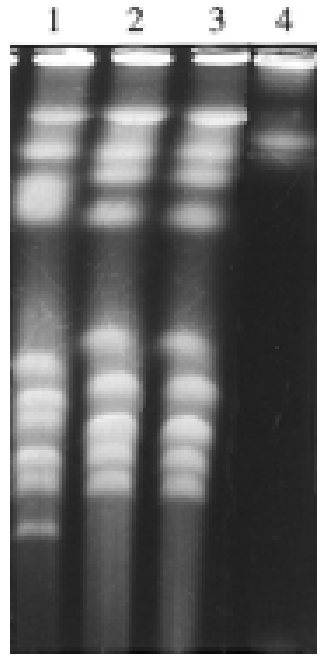

Fig. 2. Chromosomal DNA pattern of P. rhodozyma strains. Lane 1. ATCC 24203 lys, yellow, vir'; lane 2. CBS 6938 leu, vir; lane 3. CBS 6938 leu, vir $^{+}$; lane 4. Schizosaccharomyces pombe $972 \mathrm{~h}^{-}$ 


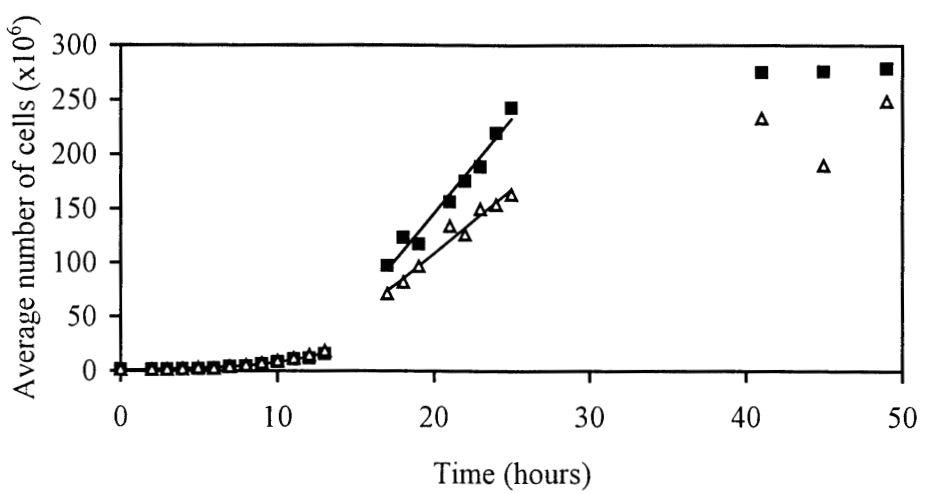

Fig. 3. Growth curve of the strains CBS $6938 l e u$, vir ${ }^{-}$and CBS $6938 l e u$, vir'. $\mathbf{~ : ~ v i r - , ~} \triangle:$ vir $^{+}$strain

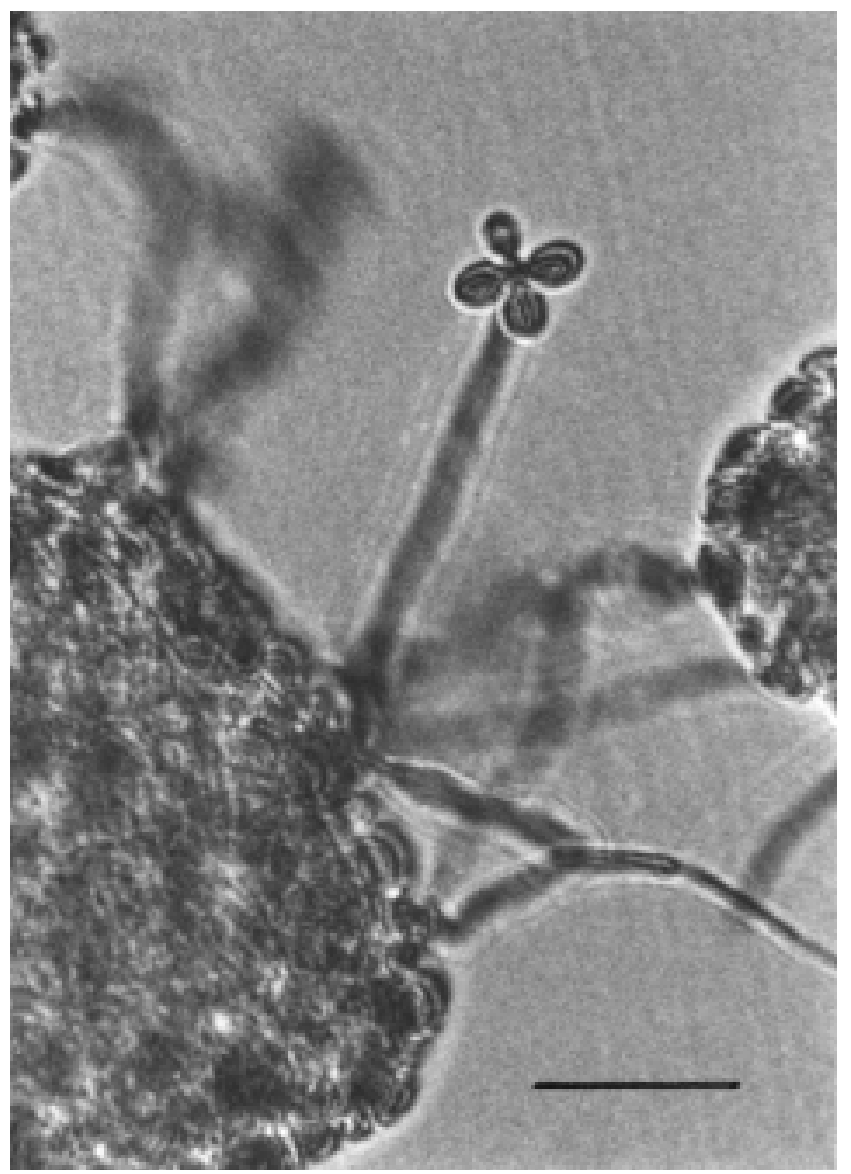

Fig. 4. Basidiospore formation of the newly created strain CBS $6938 \mathrm{leu}$, vir'. The bar represents $500 \mu \mathrm{m}$ 
Table 1

Statistical analysis of the growth in the lag and log phases

\begin{tabular}{|c|c|c|c|c|c|}
\hline \multirow{2}{*}{$\begin{array}{l}\text { Time } \\
\text { (hours) }\end{array}$} & \multicolumn{2}{|c|}{$\operatorname{vir}^{+}$} & \multicolumn{2}{|c|}{ vir } & \multirow{2}{*}{$\begin{array}{c}t \text {-test } \\
\text { (two-tailed) }\end{array}$} \\
\hline & $\mathrm{n}$ & $r^{2}$ & $\mathrm{n}$ & $r^{2}$ & \\
\hline $2-13$ & 12 & 0.96 & 12 & 0.96 & $0.1036^{\mathrm{NS}}$ \\
\hline $2-13$ & 12 & 0.99 & 12 & 0.99 & $2.43 * *$ \\
\hline $2-13$ & 12 & 0.98 & 12 & 0.98 & $0.25^{\mathrm{NS}}$ \\
\hline $13-22$ & 10 & 0.93 & 10 & 0.97 & $0.76^{\mathrm{NS}}$ \\
\hline $17-25$ & 8 & 0.98 & 8 & 0.95 & $1.75^{\mathrm{NS}}$ \\
\hline $23-33$ & 6 & 0.98 & 6 & 0.89 & $0.1^{\mathrm{NS}}$ \\
\hline 19-29 & 6 & 0.95 & 6 & 0.92 & $0.68^{\mathrm{NS}}$ \\
\hline $13-23$ & 6 & 0.84 & 6 & 0.72 & $0.58^{\mathrm{NS}}$ \\
\hline
\end{tabular}

2-13 hours: lag phase (exponential regression); 13-33 hours: log phase (linear regression)

$\mathrm{n}$ : number of points. $\mathrm{r}^{2}$ : coefficient of determination. $t$ : Student's $t$ value for slopes. NS: not significant. **: $0.01>p>0.001$

Table 2

Analysis of variance in the stationary phase

(a) Duration: 24-29 hours

\begin{tabular}{lrc}
\hline \multicolumn{1}{c}{$\begin{array}{c}\text { Source } \\
\text { of variation }\end{array}$} & DF & MS \\
\hline Infection & 1 & $2097.496^{* * *}$ \\
Time & 5 & $13.542^{* *}$ \\
Interaction & 5 & $8.800^{\mathrm{NS}}$ \\
Residual & 470 & 3.978 \\
Total & 481 & 8.441 \\
\hline
\end{tabular}

(b) Duration: 41-49 hours

\begin{tabular}{lrc}
\hline \multicolumn{1}{c}{$\begin{array}{c}\text { Source } \\
\text { of variation }\end{array}$} & DF & MS \\
\hline Infection & 1 & $359.622^{* *}$ \\
Time & 2 & $50.161^{\mathrm{NS}}$ \\
Interaction & 2 & $39.826^{\mathrm{NS}}$ \\
Residual & 125 & 36.173 \\
Total & 130 & 39.185 \\
\hline
\end{tabular}

DF: degrees of freedom. MS: mean square. NS: not significant. $* * *: \mathrm{p}<0.001 . * *: 0.01>\mathrm{p}>0.001$ 
analysis showed no difference in the growth rates of the strains (Table 1), while the virus-infected strain had a significantly lower cell number in the stationary phase than the virus-free strain (Table 2).

The effect of virus infection on the sexual reproduction was studied via the recombination, sporulation and conjugation frequency of the strains. Nineteen independent experiments were carried out (Fig. 4). Data were compared by the $\chi^{2}$ test. In 7 cases the conjugation frequency proved to be independent of the infection $\left(\chi^{2}\right.$ test, $\mathrm{df}=1$, $p>0.05$ ), but in all other cases the infection decreased the conjugation efficiency of the strain. Overall, the conjugation frequency of the vir strain was $0.72 \%$, while that of the vir ${ }^{+}$strain was $0.2 \%$.

The recombination was $0.075 \%$ in the vir strain and $0.143 \%$ in the $\operatorname{vir}^{+}$strain.

\section{DISCUSSION}

The mode of transmission determines the host-parasite relation [6]. Viruses transmitted mainly horizontally reduce the fitness of their host [5], while vertical transmission allows the evolution of benevolent viruses [2].

Insufficient data are available on the evolution of fungal viruses. In Aspergillus nidulans it has been demonstrated that viruses effectively spread via conidiospores but are excluded from ascospores. In this case, viruses did not have any effect on the host fitness [4]. Cryphonectria parasitica contains mitochondrial dsRNA elements that are effectively transmitted via the conidiospores and also the sexual spores [17]. In contrast dsRNA viruses of another plant pathogenic fungus, Magnaporthe grisea, are inherited at low frequency through the ascospores [3]. There are no data concering the sporulation ability of Ustilago maydis, but the viability of the spores was not reduced after infection [8].

DsRNA viruses with no overt phenotypic effect on the cells have been detected in P. rhodozyma. In our study, we investigated whether the virus infection has any influence on the fitness of the host. The viruses were transmitted by protoplast fusion. The growth rates of the strains in the exponential phase were not affected after the infection, but the maximum cell numbers was slightly reduced in the virus-containing strain. The results concerning basidiospore formation were inconclusive (although there was a tendency for the infection to decrease the sporulation ability), but all of the examined progenies were virus-infected [16]. Despite the fact that the infection decreased the cell number and the basidiospore formation, this study supports the idea that viruses of $P$. rhodozyma are benevolent and there is a mutualistic or neutral relation between the yeast cells and their viruses.

\section{ACKNOWLEDGEMENT}

This work was supported by grants \#I/6 T 025849 and F 020870 from the Hungarian Scientific Research Fund (OTKA). 


\section{REFERENCES}

1. Buck, K. W. (1986) Fungal virology - an overview. In: Buck, K. W. (ed.) Fungal Virology. CRC Press, Boca Raton, Florida.

2. Bull, J. J., Molineux, I. J., Rice, W. R. (1991) Selection of benevolence in a host-parasite system. Evolution 45, 875-882.

3. Chun, S. J., Lee, Y. H. (1997) Inheritance of dsRNAs in the rice blast fungus, Magnaporthe grisea. FEMS Microbiol. Lett. 15, 159-162.

4. Coenen, A., Kevei, F., Hoekstra, R. (1997) Factors effecting the spread of double stranded RNA viruses in Aspergillus nidulans. Genet. Res. 69, 1-10.

5. Ewald, P. W. (1994) Evolution of infectious disease. Oxford University Press, Oxford.

6. Frank, S. A. (1996) Models of parasite virulence. The Quarterly Review of Biology 71, 37-78.

7. Golubev, W. I. (1995) Perfect state of Rhodomyces dendrorhous (Phaffia rhodozyma). Yeast 11, $101-110$.

8. Koltin, Y., Day, P. R. (1976) Inheritance of killer phenotypes and double-stranded RNA in Ustilago maydis. Proc. Natl. Acad. Sci. USA 73, 594-598.

9. Kreger-van Rij, N. J. W. (1984) The yeasts - a taxonomic study. Elsevier Science Publishers B. V. Amsterdam.

10. Kucsera, J., Pfeiffer, I., Ferenczy, L. (1998) Homothallic life cycle in the diploid red yeast Xanthophyllomyces dendrorhous (Phaffia rhodozyma). Antonie van Leeuwenhoek 73, 163-168.

11. Lecoq, H., Boissonnet-Menes, M., Delhotal, P. (1979) Infectivity and transmission of fungal viruses. In: Molitoris, P., Hollings, M., Wood, H. A. (eds) Fungal viruses. Springer-Verlag, Berlin, pp. 34-37.

12. Maráz, A., Kiss, M., Ferenczy, L. (1978) Protoplast fusion in Saccharomyces cerevisiae strains of identical and opposite mating types. FEMS Microbiol. Lett. 3, 319-322.

13. Miller, M. W., Yoneyama, M., Soneda, M. (1976) Phaffia, a new yeast genus in the Deuteromycotina (Blastomycetes). Int. J. Syst. Bacteriol. 26, 286-291.

14. Mims, C. A. (1981) Vertical transmission of viruses. Microbiol. Rev. 45, 267-286.

15. Nagy, Á., Garamszegi, N., Vágvölgyi, Cs., Ferenczy, L. (1994) Electrophoretic karyotypes of Phaffia rhodozyma strains. FEMS Microbiol. Lett. 123, 315-318.

16. Pfeiffer, I., Kucsera, J., Varga, J., Párducz, Á., Ferenczy, L. (1996) Variability and inheritance of double-stranded RNA viruses in Phaffia rhodozyma. Curr. Genet. 30, 294-297.

17. Polashock, J. J., Bedker, P. J., Hillman, B. I. (1997) Movement of a small mitochondrial doublestranded RNA element of Cryphonectria parasitica: ascospore inheritance and implications for mithochondrial recombination. Mol. Gen. Genet. 256, 566-571.

18. Wickner, R. B. (1991) Yeast RNA virology: The killer systems. In: Broach, J. R., Pringle, J. R., Jones E. W. (eds) The molecular and cellular biology of the yeast Saccharomyces. Cold Spring Harbor Laboratory Press, New York 263-296. 